\title{
Atomic Species Associated with the Portevin-Le Chatelier Effect in Superalloy 718 Studied by Mechanical Spectroscopy
}

\author{
B. MAX, J. SAN JUAN, M.L. NÓ, J.M. CLOUE, B. VIGUIER, and E. ANDRIEU
}

In many Ni-based superalloys, dynamic strain aging (DSA) generates an inhomogeneous plastic deformation resulting in jerky flow known as the Portevin-Le Chatelier (PLC) effect. This phenomenon has a deleterious effect on the mechanical properties and, at high temperature, is related to the diffusion of substitutional solute atoms toward the core of dislocations. However, the question about the nature of the atomic species responsible for the PLC effect at high temperature still remains open. The goal of the present work is to answer this important question; to this purpose, three different 718 -type and a 625 superalloy were studied through a nonconventional approach by mechanical spectroscopy. The internal friction (IF) spectra of all the studied alloys show a relaxation peak $P_{718}$ (at $885 \mathrm{~K}$ for $0.1 \mathrm{~Hz}$ ) in the same temperature range, $700 \mathrm{~K}$ to $950 \mathrm{~K}$, as the observed PLC effect. The activation parameters of this relaxation peak have been measured, $E_{\mathrm{a}}\left(P_{718}\right)=2.68 \pm 0.05 \mathrm{eV}, \tau_{0}=2 \cdot 10^{-15} \pm{ }^{1} \mathrm{~s}$ as well as its broadening factor $\beta=1.1$. Experiments on different alloys and the dependence of the relaxation strength on the amount of Mo attribute this relaxation to the stress-induced reorientation of Mo-Mo dipoles due to the short distance diffusion of one Mo atom by exchange with a vacancy. Then, it is concluded that Mo is the atomic species responsible for the high-temperature PLC effect in 718 superalloy.

https://doi.org/10.1007/s11661-018-4579-2

(c) The Minerals, Metals \& Materials Society and ASM International 2018

\section{INTRODUCTION}

DYNAMIC strain aging (DSA) is a common phenomenon appearing in a large number of alloys and leading to a modification of mechanical properties of the materials. Since the works of Cottrell ${ }^{[1]}$ and Cottrell and Jaswon, ${ }^{[2]}$ DSA has been considered as resulting from the elastic interaction between diffusing solute atoms and the stress field surrounding mobile dislocations. Over wide ranges of temperature and strain rate, DSA generates inhomogeneous plastic deformation known as the Portevin-Le Chatelier (PLC) effect, serrated

B. MAX is with the CIRIMAT, Universite de Toulouse, UPS-INPCNRS, INP/ENSIACET, 4 Allée Emile Monso, BP 44362, 31030 Toulouse Cedex 4, France, and is now with IRT Saint Exupéry, Bât B612, 3 rue Tarfaya, CS 34436, 31405 Toulouse Cedex 4, France. J. SAN JUAN is with the Dpt. Física Materia Condensada, Facultad de Ciencia y Tecnología, Universidad del País Vasco, UPV/EHU, Apdo. 644, 48080 Bilbao, Spain. Contact e-mail: jose.sanjuan@ehu.es M.L. NO is with the Dpt. Física Aplicada II, Facultad de Ciencia y Tecnología, Universidad del País Vasco, UPV/EHU, Apdo. 644, 48080 Bilbao, Spain. J.M. CLOUE, B. VIGUIER, and E. ANDRIEU are with the CIRIMAT, Universite de Toulouse, UPS-INP-CNRS, INP/ ENSIACET.

Manuscript submitted October 4, 2017.

Article published online March 26, 2018 yielding, or jerky flow. The occurrence of the PLC effect is characterized by repeated abrupt stress drops on the stress-strain curve of tensile tests, called serrations.

This peculiar manifestation of DSA was observed, studied, and characterized in a great variety of alloys, among which there were some Ni-base superalloys. For instance, serrated plastic flow was reported in Waspalloy (United Technologies Corporation, Farmington, CT) ${ }^{[3,4]}$ alloy 625 (Special Metals Corporation, Portland, OR) ${ }^{[5-7]}$ Udimet 720 (Special Metals Corporation, Portland, OR) ${ }^{\left[{ }^{[89}\right.}{ }^{\text {Inconel }} 738$ (Special Metals Corporation, Portland, OR) ${ }^{[10]}$ and Inconel 718 (Special Metals Corporation, Portland, OR).$^{[3,11-20]}$ Many studies have been carried out on this subject of interest contributing to a better understanding of the mechanisms and atomic species potentially involved in the occurrence of the phenomenon. The characterization of the PLC effect is based on the determination of the apparent activation energy for the occurrence of serrations on stress-strain curves and its comparison with the diffusion energy of different solute species in the alloy, which allows determination of the nature of the solute atom responsible for the interaction with mobile dislocations.

In alloy 718 (Special Metals Corporation, Portland, OR), the critical strain to the onset of the first serration, $\varepsilon_{\mathrm{c}}$, evolves with temperature and strain rate following 
two different trends depending on the metallurgical condition of the alloy. ${ }^{[11,14,18,19]}$ These domains of $\varepsilon_{\mathrm{c}}$ evolution are often called normal and inverse behaviors, as shown in Figure 1, adapted from a previous work. ${ }^{[20]}$ As a reminder, in the normal domain (low temperature), $\varepsilon_{\mathrm{c}}$ decreases with an increase of temperature, whereas in the inverse domain (high temperature), $\varepsilon_{\mathrm{c}}$ increases with an increase of temperature. These two domains logically involve two distinct mechanisms responsible for the behavior at low and high temperature, and both of them have been studied on alloys in several metallurgical conditions. From a large survey of the literature, the following points appear to be relevant.

The interaction between carbon atmospheres and mobile dislocations is widely accepted, since the works of Nakada and $\mathrm{Keh}^{[21]}$ on Ni containing various levels of $\mathrm{C}$, as responsible for the low-temperature PLC effect in a great majority of Ni-based alloys. Particularly, in alloy 718 , it seems that a consensus has been reached on the subject. ${ }^{[3,11-14,18-20]}$

However, the origin of the high-temperature behavior is still a source of controversy, and opinions on the possible origin of serrations are divided. Whereas it is generally accepted that in the inverse domain, behavior of the PLC effect must be attributed to a substitutional atomic species, there are strong discrepancies about the nature of such solute. Hale et al. ${ }^{[13]}$ considered $\mathrm{Cr}$ as a potential candidate on the basis of activation energy calculations, whereas Hayes and Hayes ${ }^{[3]}$ suggested it was $\mathrm{Nb}$, based on the disappearance of serrations for high strains resulting from the depletion of $\mathrm{Nb}$ in the stress field of dislocations due to the formation of $\mathrm{NbC}$ clusters during deformation. Nalawade et al. ${ }^{[18,19]}$ working on different metallurgical conditions of alloy 718 ,

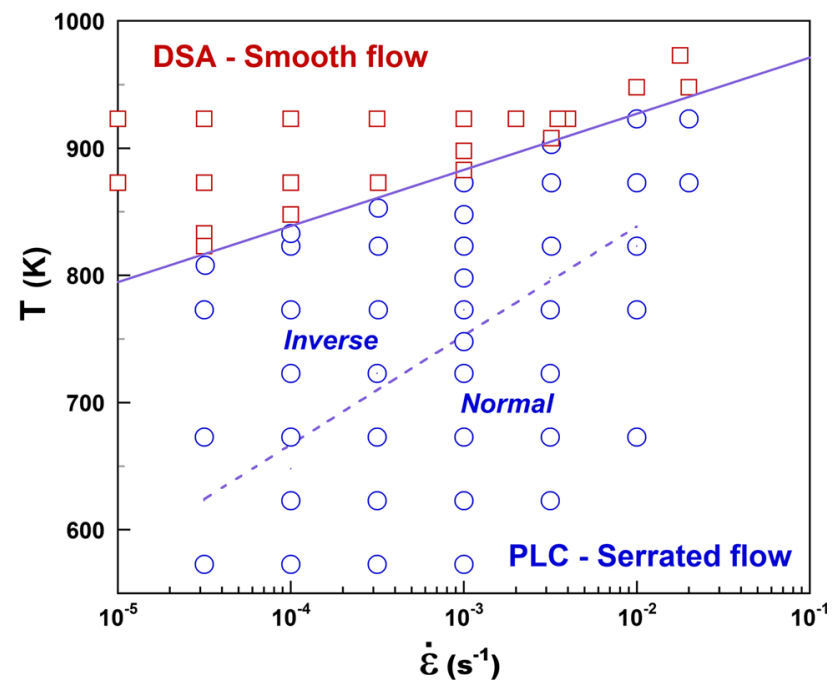

Fig. 1-Map of plastic deformation mechanisms, in the temperature-strain rate plane, for the 718 alloy, after precipitation through the standard aeronautic thermal treatment. DSA refers to the domain where no serrations are observed (red squares), whereas PLC denotes the domain in which serrated flow is observed (blue circles); a dashed line is plotted between the inverse and normal behaviors of the critical strain to the onset of serrations. Adapted from previous results ${ }^{[20]}$ (Color figure online). claimed that $\mathrm{Nb}$ is the atom responsible for the high-temperature PLC phenomenon. The reason was the earlier disappearance of serrations when increasing tensile test temperatures in samples with a matrix containing less $\mathrm{Nb}$ (i.e., aged and $\delta$ precipitated) than in the solution-treated material. Nevertheless, this study is based on the comparison of the plastic behavior of alloys in totally different metallurgical conditions, which could lead to misleading interpretation of the experimental results.

A recent study of the PLC effect on a cast alloy $718,{ }^{[20]}$ aged by a standard aeronautical heat treatment $(993 \mathrm{~K} / 8 \mathrm{~h}-893 \mathrm{~K} / 8 \mathrm{~h})$, allowed evaluation of the apparent activation energies of the high-temperature PLC effect using the different methods described in the literature. ${ }^{[3,13,14,22,23]}$ Unfortunately, the activation energies calculated by these five methods fluctuate between 110 and $320 \mathrm{~kJ} / \mathrm{mol}$ (1.14 and $3.32 \mathrm{eV}$, respectively). These results are consistent with the values obtained on other 718 alloys, in different metallurgical conditions, and corresponds to the activation energy for the diffusion of some substitutional atomic species. Nevertheless, the diffusion energies of substitutional solutes in Ni-based alloys are close to one another (Table S1 in the Supplementary Material), and all of them fall in the measured range. Consequently, the important question, of high scientific and technological interest, about the atomic species responsible for the high-temperature PLC effect remains open.

Then the aim of the present work is to answer the preceding question and close the controversy about the nature of the atoms diffusing toward dislocations in the temperature range in which the high-temperature PLC effect is observed, which, according to Figure 1, takes place between $700 \mathrm{~K}$ and $950 \mathrm{~K}$. To reach this goal, another experimental technique was considered as promising insofar as the objective of answering this question is concerned. Indeed, the study was approached by mechanical spectroscopy, which is a powerful technique to study the mobility of atomic structural defects and, in particular, point defects. ${ }^{[24-26]}$ It is expected that the short distance diffusion of the mobile solute atoms in the Ni lattice could give place to a relaxation peak in the internal friction (IF) spectrum measured by mechanical spectroscopy, making possible access to the activation energy of the relaxation process. The term "short distance diffusion" is used as a generalization of the atomic jumps at nearest-neighbor (NN) or next-NN distances, constituting the elemental mechanism for the long distance diffusion processes. The formal theory establishing the relationship between the atomic jumps measured during anelastic relaxation and the diffusion theory, according to Fick's law, can be found in classic texts. ${ }^{[24,25]}$ The idea is to establish a link between the short distance diffusion responsible for the anelastic relaxation phenomenon, measured by mechanical spectroscopy, and the long distance atomic diffusion responsible for the inhomogeneous plastic deformation observed during the PLC and characterized by tensile tests. We expect that this approach, applied to a series of different 718-based alloys, will allow us elucidate the nature of the atomic diffusing species. 


\section{MATERIALS AND METHODS}

Four alloys were studied by mechanical spectroscopy: alloy 718 , solid solution treated and further aged; two 718-like prototype alloys, one without $\mathrm{Nb}$ and the other enriched in Mo; and, finally, an alloy $625+$. The chemical compositions of the different alloys used in this study are summarized in Table I. The choice of such different alloys and treatments was made with the purpose of having different content of atomic solutes, in particular, $\mathrm{Nb}, \mathrm{Fe}$, and $\mathrm{Mo}$, in comparable microstructural conditions.

Alloy 718 is a cold-rolled 0.65 -mm-thick strip. Some samples were solid solution treated (718SS) during 1 hour at $1333 \mathrm{~K}$ and then water quenched, whereas other samples were further aged (718AP) following the conventional aeronautical aging heat treatment, $993 \mathrm{~K} / 8$ hour-893 K/8 hour, to produce the precipitation of $\gamma^{\prime}$ and $\gamma^{\prime \prime}$ phases; the grain size of these alloys is about 10 to $20 \mu \mathrm{m}$. A prototype $\mathrm{Nb}$-free 718 alloy $(718 \mathrm{NbF})$ was specifically produced and hot rolled to 20 -mm-thick plates; finally, it was cold rolled and annealed at $1273 \mathrm{~K}$ during 60 seconds. The grain size is about 15 to $30 \mu \mathrm{m}$. Another prototype 718 alloy enriched in Mo (718Mo) was produced and hot rolled to 8-mm-thick plates. Samples were cut from as-received material and aged following the conventional aeronautical aging heat treatment, $993 \mathrm{~K} / 8$ hour $-893 \mathrm{~K} / 8$ hour; the grain size of this alloy is about $50 \mu \mathrm{m}$. Alloy $625+$ was cold rolled to 4-mm-thick plates and then solution treated during 30 minutes at $1273 \mathrm{~K}$. Finally, samples received a specific aging heat treatment, $1003 \mathrm{~K} / 8$ hour $-903 \mathrm{~K} / 8$ hour; the grain size of this alloy is about $100 \mu \mathrm{m}$. All final heat treatments were made on $\mathrm{Fe}-\mathrm{Cr}-\mathrm{Al}-\mathrm{Y}$ wraps sealed under vacuum, $5 \times 10^{-5}$ mbar.

Samples for IF measurements were cut using an abrasive disc saw in the case of the 718 standard alloy and the $718 \mathrm{Nb}$-free prototype alloy and by electrodischarge machining (EDM) in the case of the 718 Mo-enriched prototype alloy and the alloy $625+$. Samples machined by EDM were mechanically ground over at least $150 \mu \mathrm{m}$ to remove the heat-affected zone. All samples were finally polished on silica carbide papers until 1200 grade. The length and width of the samples for IF measurements were $50 \times 5 \mathrm{~mm}$, and their thickness was between 0.7 and $0.5 \mathrm{~mm}$.

The IF and dynamic modulus variation (DMV) measurements were carried out in a forced subresonant torsion pendulum, able to work as a function of frequency in the range 0.01 to $3 \mathrm{~Hz}$ as well as to work as a function of temperature in the range 150 to 1100 $\mathrm{K} \cdot{ }^{[27]}$ The IF is measured through the $\tan (\phi), \phi$ being the lag angle between the oscillating strain and the applied stress. In this study, the measurements were made as a function of temperature at different frequencies, with an initial oscillation amplitude at room temperature of $\varepsilon_{0}=10^{-5}$. The IF spectra and the modulus variation curves were measured under vacuum, of about $10^{-6} \mathrm{mbar}$, at a heating rate of $1 \mathrm{~K} / \mathrm{min}$. The temperature was measured by a $\mathrm{K}$ thermocouple located in the lower clamp at the basis of the IF sample.

\section{EXPERIMENTAL RESULTS AND ANALYSIS}

Initially, the IF spectra and the dynamic modulus curves on the alloy 718SS, after the solid solution treatment, were measured as a function of temperature between 300 and $1033 \mathrm{~K}$ for six different frequencies between 0.01 and $3 \mathrm{~Hz}$. The IF spectra for three frequencies are shown in Figure 2, as well as the DMV curve associated with the spectrum at the lower frequency of $0.03 \mathrm{~Hz}$. An IF peak is clearly observed, superimposed to a growing high-temperature background (HTB). The IF peak shifts to low temperature when the oscillation frequency decreases and is associated with a dynamic modulus defect; this corresponds to a relaxation peak linked to a thermally activated mechanism.

\section{A. Analysis of the Relaxation Peak}

To analyze this relaxation peak, its activation parameters must be determined, and in Figure 3(a), the spectra measured at six imposed discrete frequencies are plotted as a function of $1 / T$. Assuming that the associated thermal activated process follows the Arrhenius law for the relaxation time $\tau=\tau_{0} \cdot \exp \left(E_{\mathrm{a}} / k_{\mathrm{B}} \cdot T\right)\left(\tau_{0}\right.$ is the time limit, $E_{a}$ the activation energy, $k_{\mathrm{B}}$ the Boltzmann constant, and $T$ the temperature), and taking into account that for an oscillation of angular frequency $\omega$ the peak maximum is reached when the condition $\omega \tau=1$ is fulfilled, ${ }^{[24,25]}$ the activation energy can be obtained through Eq. [1]:

$$
\ln (\omega)=-\ln \left(\tau_{0}\right)-\frac{E_{\mathrm{a}}}{k_{\mathrm{B}}} \times \frac{1}{T}
$$

Plotting the temperature of the peak maximum $T_{\mathrm{P}}$ in $1 / T$ vs $\ln (\omega)$, a linear fit, according to Eq. [1], gives the activation energy $E_{\mathrm{a}}$. However, there is a problem from the experimental point of view, which prevents using this method from the peak maxima. Indeed, the HTB grows fast and close to the peak, given place to a slight shift of

Table I. Chemical Compositions of the Studied Nickel-Based Alloys (Weight Percent), as Measured by Glow Discharge Mass Spectrometry and Instrumental Gas Analysis

\begin{tabular}{lccccccccccc}
\hline Compositions (Wt Pct) & $\mathrm{Ni}$ & $\mathrm{Fe}$ & $\mathrm{Cr}$ & $\mathrm{Nb}$ & $\mathrm{Ti}$ & $\mathrm{Al}$ & $\mathrm{Mo}$ & $\mathrm{Mn}$ & $\mathrm{Si}$ & $\mathrm{Co}$ & $\mathrm{C}$ \\
\hline Alloy 718 & bal & 18.30 & 18.39 & 4.94 & 0.95 & 0.56 & 3.0 & 0.06 & 0.04 & 0.02 & 0.033 \\
Alloy 718 NbF & bal & 18.47 & 17.92 & $<0.001$ & 1.01 & 0.52 & 2.92 & 0.12 & 0.06 & 0.044 & 0.06 \\
Alloy 718 Mo & bal & 14.44 & 18.6 & 5.13 & 1.01 & 0.53 & 4.44 & 0.1 & 0.12 & 0.03 & 0.03 \\
Alloy 625+ & bal & 3.60 & 21 & 3.5 & 1.5 & 0.2 & 8.0 & 0.1 & 0.05 & 0.02 & 0.03 \\
\hline
\end{tabular}




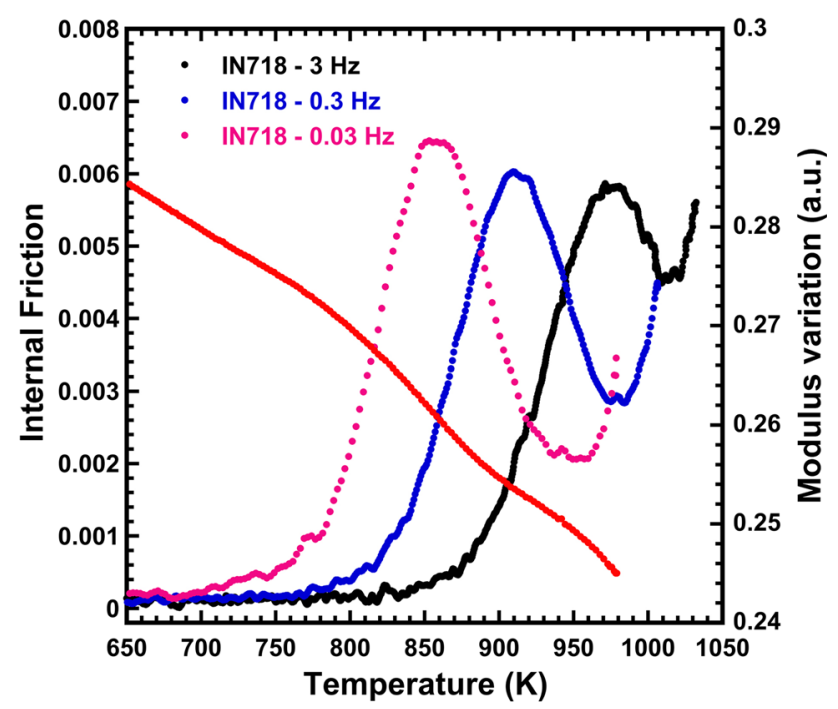

Fig. 2-IF spectra measured at three different frequencies on the 718SS alloy after the solid solution treatment. The presented curve of DMV (red dots) corresponds to the IF peak at $0.03 \mathrm{~Hz}$ (Color figure online).

the peak maxima. This problem is usually solved by fitting the expression of the HTB and subtracting it from the IF spectra, to obtain the isolated relaxation peak. Nevertheless, although this method has been successfully applied to high-temperature intermetallics, ${ }^{[28-30]}$ it cannot be applied in the present case because the HTB has been measured only in a narrow temperature range not wide enough to fit it properly. In fact, the sample must not be heated above $993 \mathrm{~K}$ for a long time, in order to avoid the precipitation processes during the thermal run along each measurement; consequently, we kept the temperature below $1010 \mathrm{~K}$ in all runs except for the last measurement at $3 \mathrm{~Hz}$. Fortunately, Eq. [1] can be applied not only to the peak maxima but to every point of the peaks, provided that the IF peaks are previously normalized, ${ }^{[24]}$ as we have done to plot Figure 3(a). Then, it can be considered a good approximation that the low-temperature side of the peaks is not, or is only slightly, affected by the HTB, and Eq. [1] can be applied to any point with the same strength from each spectrum (gray line). The Arrhenius diagram of Figure 3(b) is obtained from these points, giving the activation energy of $E_{\mathrm{a}}=2.66 \mathrm{eV}$. This plot cannot offer the value of $\tau_{0}$ from the ordinate at the origin, but it can be obtained by a simple shift in temperature to match the temperature of the peak maximum corresponding to the spectrum at the lowest frequency $(0.01 \mathrm{~Hz})$, which is practically not affected by the HTB; thus, a time limit of $\tau_{0}=1.02 \times 10^{-15} \mathrm{~s}$ is obtained. Once the activation energy is determined, the relaxation peak can be fitted to Eq. [2], which represents a relaxation peak as a function of $1 / T^{26]}$ :

$$
\tan [\phi(T)]=\tan \left[\phi_{\max }\right] \cosh ^{-1}\left\lfloor\frac{E_{a}}{r_{2}(\beta) \cdot k_{B}}\left(\frac{1}{T}-\frac{1}{T_{p}}\right)\right\rfloor
$$

where $\tan \left(\phi_{\max }\right)$ is the maximum strength of the peak and $r_{2}(\beta)=\Delta T^{-1}(\beta) / \Delta T^{-1}(0)$ is the broadening factor given by the ratio between the width of the experimental relaxation peak and the width of a theoretical single-time relaxation peak (Debye peak, $\beta=0$ ), which is directly related to the $\beta$ parameter of the Gaussian (log-normal) distribution of energies. ${ }^{[24,26]}$ This method was applied to the spectrum measured at $0.01 \mathrm{~Hz}$, for which the peak and the HTB are more split up than for other frequencies, allowing a good fit of the HTB and its subtraction from the spectrum to obtain the isolated peak.

Although this procedure must be mathematically done in $1 / T,{ }^{[26,30]}$ the final result was plotted $v s T$ in Figure 3(c), where the HTB (cyan rhombuses) and the best fit of the relaxation peak for $r_{2}=1.40$ (red dots) are shown in comparison with the experimental spectra (black squares). We have also included the associated DMV curve showing the corresponding modulus defect. With the determined parameters, activation energy $E_{\mathrm{a}}=2.66 \mathrm{eV}$, time limit $\tau_{0}=1.02 \times 10^{-15} \mathrm{~s}$, and broadening factor $r_{2}=1.40(\beta=1.3)$, the relaxation peak appearing in solid solution condition $P_{\mathrm{SS}}$ becomes fully characterized. We may conclude from the narrow distribution factor $r_{2}$ and the time limit $\tau_{0}$ that the relaxation peak $P_{S S}$ must be associated with a point defect mobility mechanism.

Along all the series of IF measurements shown in Figure 3(a), the time that the sample remains above 993 $\mathrm{K}$ is about 1.5 hours, without any noticeable evolution of the relaxation peak. However, it could be argued that during heating, while measuring between $923 \mathrm{~K}$ and $1033 \mathrm{~K}$, the precipitation of $\gamma^{\prime}\left(\mathrm{Ni}_{3} \mathrm{Al}\right)$ and $\gamma^{\prime \prime}\left(\mathrm{Ni}_{3} \mathrm{Nb}\right)$ could take place and then the relaxation peak would be, in fact, observed in the precipitated state and not in the solid solution state, in which case the relaxation peak could be associated with the precipitates. This aspect deserves a deep analysis. Although there are some differences in the transformation-time-temperature (TTT) diagrams for the precipitation of $\gamma^{\prime}$ and $\gamma^{\prime \prime}$ in 718 alloy, ${ }^{[31,32]}$ we can consider for the present analysis that the isothermal kinetics given by Brooks and Bridge ${ }^{[31]}$ for $\gamma^{\prime \prime}$ precipitation could be used as the faster one to describe the isothermal precipitation domain of either or both of the $\gamma^{\prime}$ and $\gamma^{\prime \prime}$ phases. In such TTT diagrams,${ }^{[31]}$ the precipitation in isothermal conditions at $873 \mathrm{~K}$ is extremely slow and starts at about 1000 hours of aging. As the time elapsed during the IF measurement to reach this temperature (5 hours) is completely negligible, it can be considered that, at least during the first heating run, this temperature is reached in the initial solid solution state. At $923 \mathrm{~K}$, the TTT diagram indicates that the precipitation starts after 90 minutes of isothermal aging. During IF measurement, the time required to reach this temperature from our initial state at $873 \mathrm{~K}$ is only 50 minutes; consequently, the precipitation should have not started yet. However, due to experimental uncertainties, it could be conceded that during the first measurement, the precipitation could possibly start at $923 \mathrm{~K}\left(650^{\circ} \mathrm{C}\right)$. Then, IF was measured in another virgin sample of 718 alloy in solid solution state. In Figure 3(d), the IF spectrum measured during the first heating run at $0.03 \mathrm{~Hz}$ is presented (black squares). Figure 3(d) clearly shows that the relaxation peak is fully developed and reaches its 


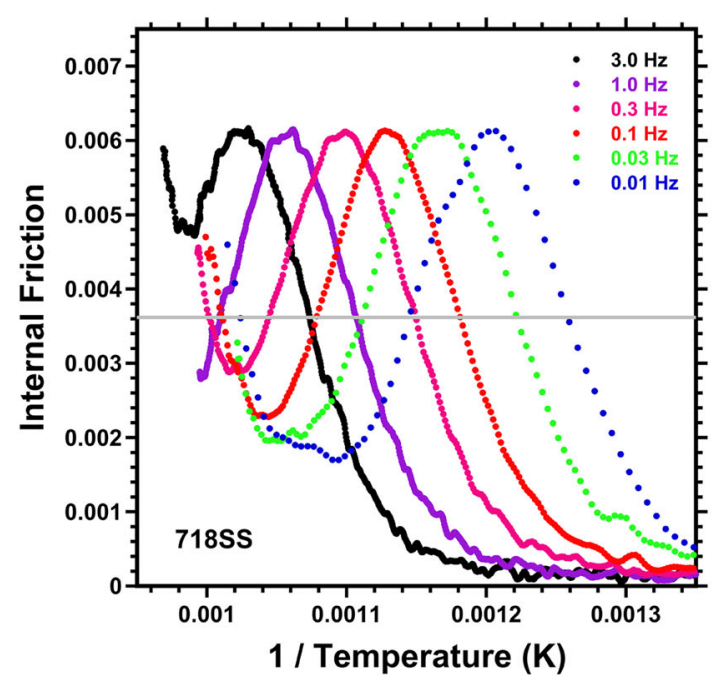

(a)

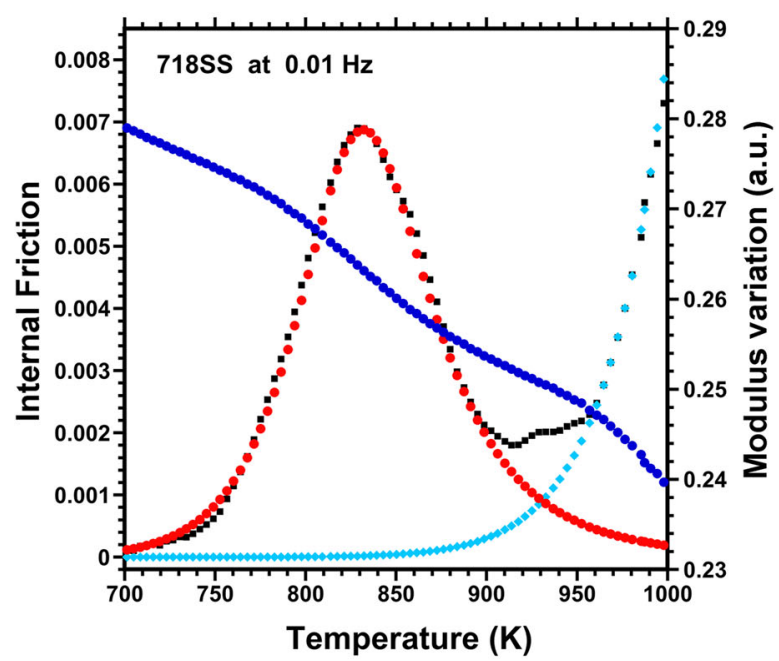

(c)

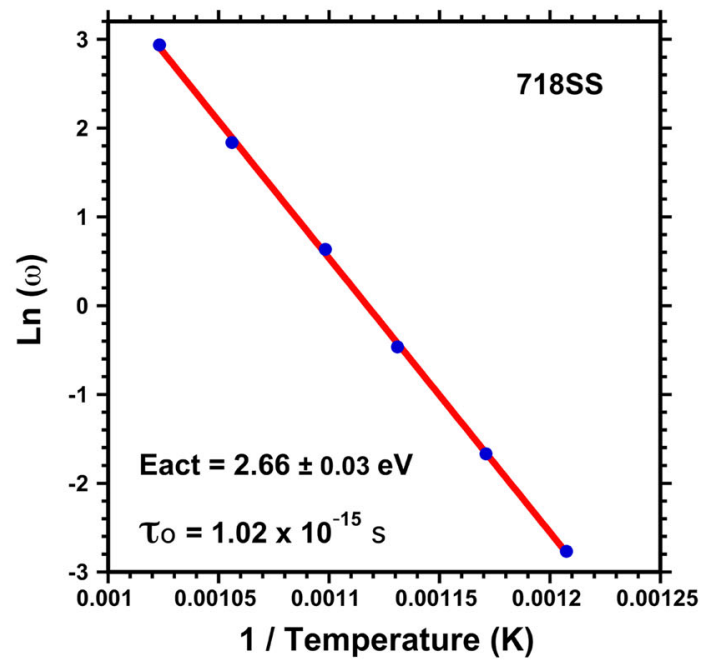

(b)

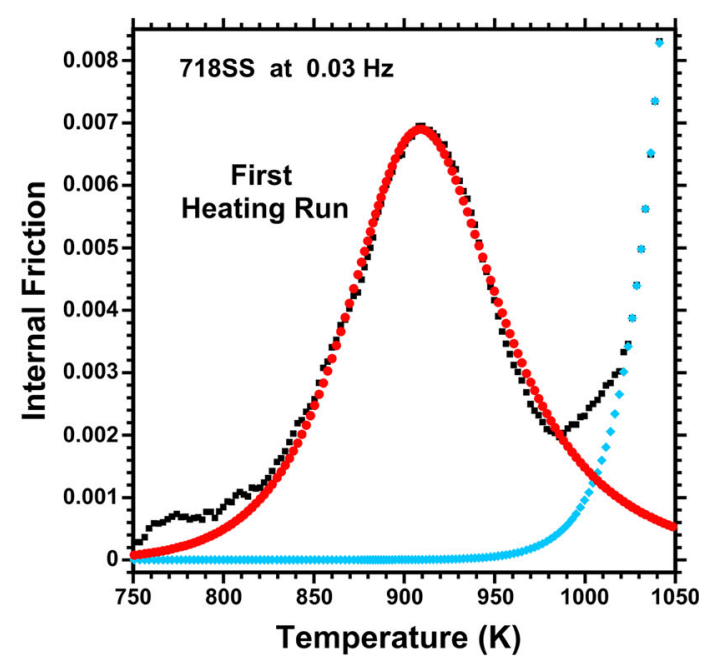

(d)

Fig. 3- (a) Complete series of IF spectra measured at different frequencies on the 718SS alloy in solid solution, after normalization to the strength of the peak at $0.1 \mathrm{~Hz}$. The gray line is the reference for measuring the temperature shift of the peak with frequency. (b) Arrhenius plot from the data of (a) and using Eq. [1]. (c) Experimental IF spectrum at $0.01 \mathrm{~Hz}$ (black squares), the subtracted HTB (cyan rhombuses), and the theoretical broadened Debye peak fitted (red dots) using Eq. [2] with the data indicated in the text. The DMV associated with this relaxation peak is also plotted (blue dots). (d) Experimental IF spectrum at $0.03 \mathrm{~Hz}$ (black squares) measured during the first heating run in a new sample of 718 alloy in solid solution, and the fit (red dots) to a broadened Debye peak with the same parameters as in (c) (Color figure online).

maximum earlier than the precipitation process even starts, and it can be concluded that the relaxation process takes place in solid solution. Even more, the theoretical broadened Debye peak (red dots), fitted with the same parameters $\left(E_{\mathrm{a}}\right.$ and $\left.r_{2}\right)$ obtained in Figure 3(c) for the IF spectrum measured after many measurements of the series presented in Figure 3(a), is also plotted in Figure 3(d) for the new virgin sample. Then, it can be concluded that, even if the precipitation takes place along thermal cycling during measurements, it does not have any substantial effect on the relaxation peak. Consequently, it can be concluded also that the IF peak is linked to a relaxation process taking place in the solid solution of the matrix.

In addition, the temperature range in which the relaxation peak spreads, $700 \mathrm{~K}$ to $950 \mathrm{~K}\left(430{ }^{\circ} \mathrm{C}\right.$ to $680^{\circ} \mathrm{C}$ ), is exactly the same as the one in which the inverse PLC effect takes place (Figure 1), and there is also a direct correlation between the IF and the strain-rate behavior during the PLC effect. It is difficult to establish a quantitative relationship between the strain rate during the PLC effect, which is linked to the mobile dislocation velocity, and the IF relaxation peak at a given frequency, which is related to the short distance atom diffusion, but a qualitative rationalization is offered as follows. The comparison between the PLC effect and the IF peak must be done for the same microstructural state; this means that the relaxation peak measured in the 718 aged (precipitated) state should be considered. The analysis of the $P_{\text {AP }}$ peak is presented in Figure 4, and in the supplementary information, (Figure $\mathrm{S} 1$ ), the reader can find the spectra in the T scale for an easy comparison.

During an imposed strain-rate deformation test (consider $\dot{\varepsilon}=3 \times 10^{-4} \mathrm{~s}^{-1}$ in Figure 1), the dislocations will 


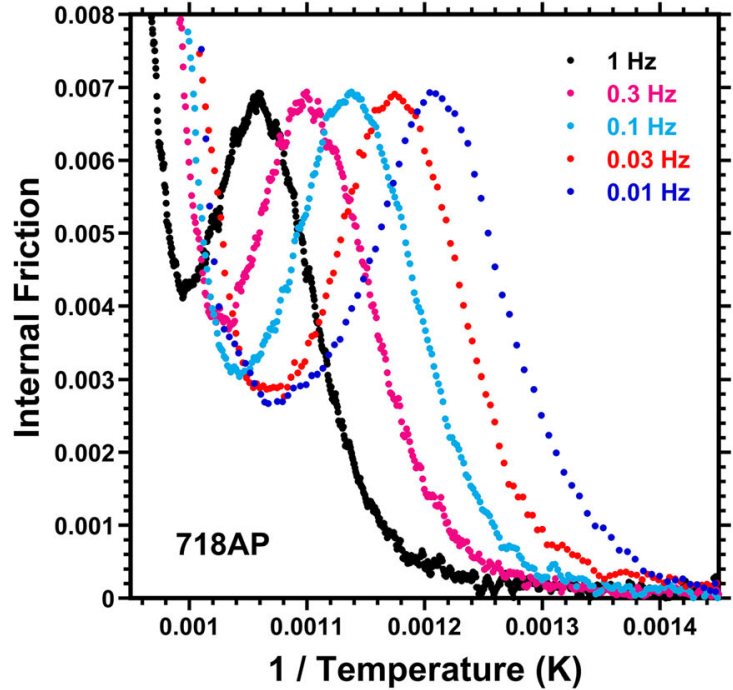

(a)

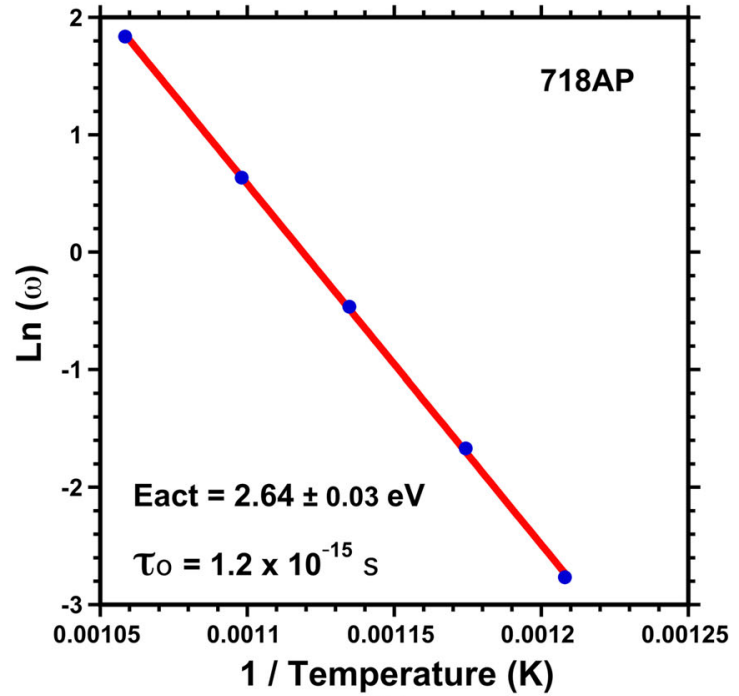

(b)

Fig. 4 - (a) Series of IF spectra measured at different frequencies on the 718 alloy after the standard aeronautical thermal treatment to promote precipitation. The spectra were normalized to the strength of the spectrum at $0.1 \mathrm{~Hz}$. (b) Arrhenius plot from the data in (a) using the same procedure as in Fig. 3 and Eq. [1].

move at a certain velocity (depending on several microstructural parameters) when one atomic species is able to diffuse. However, if the atomic diffusion velocity is lower than that of the dislocation, a repeated breakaway of the dislocation from the solute atmosphere will occur and the PLC effect appears (at about $710 \mathrm{~K}$ in Figure 1). When the diffusing atomic species are able to diffuse fast enough to follow the dislocation motion velocity, solute atoms will be dragged, and a transition from PLC to DSA will be observed (at about $855 \mathrm{~K}$ in Figure 1). During an IF measurement (consider the spectrum at $0.03 \mathrm{~Hz}$ in Figures 4 or S1), the mobility of solute atoms takes place at a strain rate imposed by the frequency, $\dot{\varepsilon} \propto f$, and the temperature of the peak is given by the resonant condition, $\omega \tau=1$. Nevertheless, this process follows the Boltzmann statistics, and for a single relaxation time $\tau$, the IF results in a Debye peak. The peak begins at a temperature at which some atoms start to move at the imposed frequency (at about $720 \mathrm{~K}$ for $0.03 \mathrm{~Hz}$ in Figures 4 or S1), so the beginning of the IF peak indicates the temperature at which the PLC effect starts. At the temperature of the peak maximum (about $850 \mathrm{~K}$ for $0.03 \mathrm{~Hz}$ in Figure 4), the resonant condition $\omega \tau=1$ means that the diffusing atoms are able to move fast enough to follow the strain rate, so the maximum of the IF peak is roughly giving the temperature of the transition from PLC to DSA. The quantitative prediction of the proportionality between the strain rate for the PLC effect and the frequency for IF is a difficult task, out of the scope of the present work, but the experimental values for PLC at $\dot{\varepsilon}=3 \times 10^{-4} \mathrm{~s}^{-1}$ match rather well with the values of IF at $0.03 \mathrm{~Hz}$. Now, let us increase one order of magnitude the strain rate for the PLC effect, $\dot{\varepsilon}=3 \times 10^{-3} \mathrm{~s}^{-1}$, in Figure 1 . In this case, the PLC effect starts at about $790 \mathrm{~K}$ and finishes at about $905 \mathrm{~K}$. Then, in order to compare it with the IF, we should also increase one order of magnitude the frequency, $0.3 \mathrm{~Hz}$, in Figures 4 (or S1). In such case, the IF peak starts at about $780 \mathrm{~K}$ and reaches maximum strength at $910 \mathrm{~K}$, so roughly at the same temperatures as the beginning and end of the PLC effect. Consequently, there is a good correlation between the temperature and the strain-rate ranges in both kinds of experiments, PLC effect and IF spectra, allowing us to conclude that the atomic species, whose short distance diffusion mobility is responsible for the IF relaxation peak, must be the same one whose long distance diffusion is responsible for the inverse PLC effect. Unfortunately, as commented previously, the diffusion energies of the different atomic species candidates for being responsible for the inverse PLC, this means $\mathrm{Ti}^{[33,34]}$ $\mathrm{Al},{ }^{[33,35,36]} \mathrm{Nb},{ }^{[37,38]} \mathrm{Fe},{ }^{[33,39-41]} \mathrm{Cr}{ }^{[40,42,43]}$ and $\mathrm{Mo},{ }^{[38,43-45]}$ are close to one another (Table S1 in the supplementary information). Consequently, the measured activation energy does not allow us to discriminate between the atomic species responsible for the relaxation peak and the PLC effect. This will be done through the next series of experiments.

\section{B. Influence of Solute on the Relaxation Peak}

To identify the atomic species responsible for the observed relaxation, we have to consider that, according to the main reviews on anelastic relaxations due to point defects, ${ }^{[24,46-48]}$ the relaxation strength increases with the concentration of solute atoms in solid solution, irrespective of the particular atomic mechanism responsible for the relaxation. With that basic idea in mind, the evolution of the relaxation peak will be followed as a function of the concentration of the different solute atoms. First, the influence of $\mathrm{Ti}$ and $\mathrm{Al}$ on the relaxation will be tested. As $\mathrm{Ti}$ and $\mathrm{Al}$ are involved in the formation of the $\gamma^{\prime}$ precipitates, their proportion in the matrix decreases greatly from the solid solution state to 
the precipitated state. This was experimentally determined in 718 alloy by atom probe tomography, ${ }^{[49]}$ showing that during the aging of the standard aeronautical thermal treatment, the amount of $\mathrm{Ti}$ and $\mathrm{Al}$ in solid solution in the matrix falls to less than 25 at. pct of the initial concentration. Consequently, after applying the aging treatment to promote the precipitation in our alloy 718 , a strong decrease of the relaxation strength would be expected if $\mathrm{Ti}$ or $\mathrm{Al}$ were responsible for the relaxation peak. In Figure 4(a), the IF spectra of the precipitated alloy 718AP are shown for five frequencies, and from them, the Arrhenius diagram of Figure 4(b) was obtained by the method described previously. The measured activation parameters are the same, within the error range, and it can be asserted that the $P_{\mathrm{AP}}$ (after precipitation) peak corresponds to the one observed in solid solution $P_{\mathrm{SS}}$.

Nevertheless, in the precipitated state, the strength of the peak $P_{\mathrm{AP}}$ not only has not decreased but it is even slightly higher than the previous peak in solid solution $P_{\text {SS }}$. It could be argued that during the precipitation treatment in 718 alloy, two kinds of ordered precipitates were formed, namely, $\gamma^{\prime}\left(\mathrm{Ni}_{3} \mathrm{Al}\right)$ and $\gamma^{\prime \prime}\left(\mathrm{Ni}_{3} \mathrm{Nb}\right)$, the second one being much more abundant than the former. An IF peak was observed in $\mathrm{Ni}_{3} \mathrm{Al}$ alloys. ${ }^{[50-53]}$ However, this relaxation peak was attributed to a Zener-like mechanism of Al-antisite atoms ${ }^{[51,52]}$ in Al-rich $\mathrm{Ni}_{3} \mathrm{Al}$ alloys, and its strength decreased strongly for concentrations below the stoichiometry composition, as reported for 23.5 (at. pct) $\mathrm{Al},{ }^{[50]}$ or was even not detected for 24.1 (at. pct) Al. ${ }^{[53]}$ In the present case of the 718 alloy, the concentration of the $\gamma^{\prime}$ precipitates, after the aging aeronautic heat treatment, is about 9 (at.

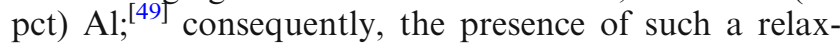
ation peak in $\gamma^{\prime}$ precipitates can be discarded. In any case, if the relaxation peak is associated with the $\gamma^{\prime}$ precipitates, it should be absent in the 625 alloy; on the contrary, the peak is still higher in this alloy, as will be presented subsequently. Then, it can be concluded that $\mathrm{Ti}$ and $\mathrm{Al}$ are not the solute atoms responsible for the relaxation peak and, consequently, neither for PLC effect. To the best of our best knowledge, no IF peak associated to $\gamma^{\prime \prime}$ precipitates has been reported. However, the $\gamma^{\prime \prime}$ precipitation has a strong influence on the concentration of $\mathrm{Nb}$ in solid solution. The fact that IF peaks have similar characteristics in both solid solution and precipitated states is a first indication that $\mathrm{Nb}$ is not directly involved in the IF peak. Then, in order to really test the influence of $\mathrm{Nb}$, a prototype $\mathrm{Nb}$-free alloy $718 \mathrm{NbF}$ was specifically produced, as indicated in Table I. In Figure 5, the IF spectrum measured in the $718 \mathrm{NbF}$ alloy, which is in solid solution state, is presented in comparison with the spectrum of 718SS alloy, both at a frequency of $0.1 \mathrm{~Hz}$. As in the case of the $718 \mathrm{SS}$ alloy, the peak is also fully developed in the $718 \mathrm{NbF}$ alloy even during the first heating run at $1 \mathrm{~Hz}$ (Figure S2 in the Supplementary Information). Apart from the small variation of the HTB, the relaxation peak remains unchanged after the suppression of $\mathrm{Nb}$. Hence, it can be concluded that the relaxation peak cannot be related to the $\gamma^{\prime \prime}\left(\mathrm{Ni}_{3} \mathrm{Nb}\right)$ precipitates, appearing only in $\mathrm{Nb}$ bearing alloys. In addition, it also becomes obvious

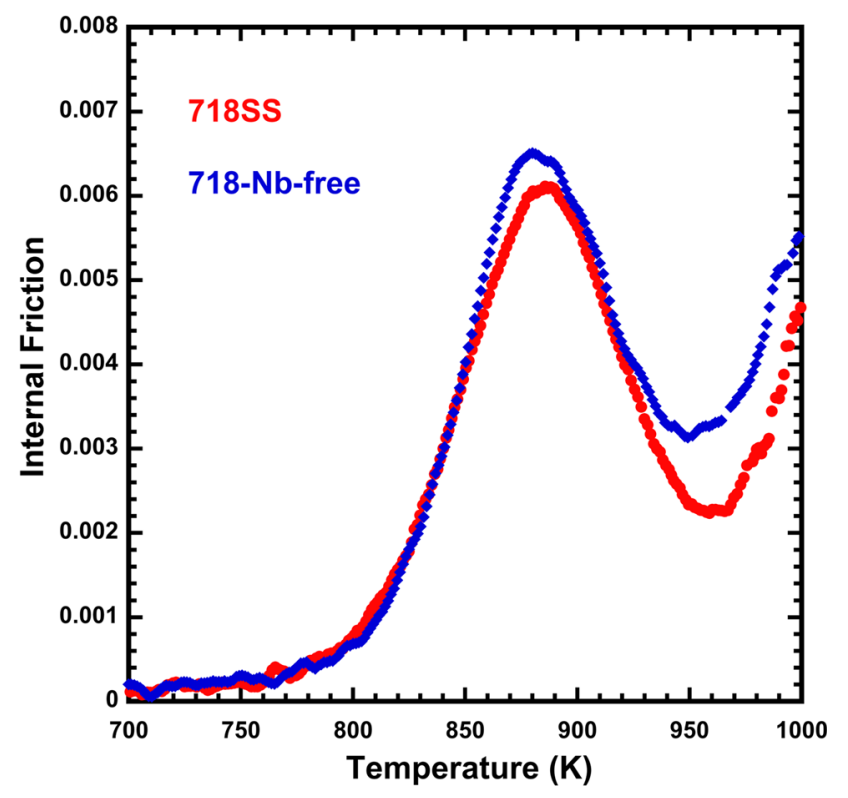

Fig. 5-Comparison of the IF spectra at $0.1 \mathrm{~Hz}$, measured in the alloy 718 in solid solution (718SS, red dots) and in the prototype $718 \mathrm{Nb}$-free alloy (718 Nb-free, blue rhombuses) (Color figure online).

that $\mathrm{Nb}$ is not the solute responsible for the relaxation peak and, consequently, neither for the PLC effect, in agreement with previous results ${ }^{[54]}$ in which the PLC effect was also observed in the same $\mathrm{Nb}$-free alloy $718 \mathrm{NbF}$.

In what concerns the other solute elements $\mathrm{Cr}, \mathrm{Fe}$, and Mo, it should be remarked that $\mathrm{Cr}$ and $\mathrm{Fe}$ produce a small change in the lattice parameters of the binary $\mathrm{Ni}-\mathrm{X}$ alloys ${ }^{[55]}$ even for high concentrations. This means that $\mathrm{Cr}$ and $\mathrm{Fe}$ should produce small local distortions of the Ni lattice; consequently, their contribution to a possible anelastic relaxation should be small. Indeed, IF measurements in binary $\mathrm{Ni}-\mathrm{Cr}$ polycrystalline and single-crystal alloys between 20 and 33 at. pet $\mathrm{Cr}^{[56]}$ show that only a small IF peak about $1.4 \times 10^{-3}$ in strength, attributed to the Zener relaxation of $\mathrm{Cr}$ with an activation energy of $2.92 \mathrm{eV}$, appears in these high-Cr bearing alloys. Consequently, it can be concluded that $\mathrm{Cr}$, even though it could have some small contribution to the IF spectra close to the HTB, cannot be responsible for the observed relaxation peak. A new prototype Mo-rich alloy $718 \mathrm{Mo}$ was specifically produced to test the influence of Mo, the concentration of which $(4.44 \mathrm{wt}$ pct Mo) is reported in Table I. This alloy underwent the standard aeronautical thermal treatment and is in the precipitated state. Three IF spectra measured at different frequencies in this $718 \mathrm{Mo}$ alloy are plotted in Figure 6(a), and using Eq. [1], the Arrhenius diagram is plotted in Figure 6(b).

The activation energy of this peak $P_{\mathrm{Mo}}$ is the same as the one previously measured for $P_{\mathrm{SS}}$ or $P_{\mathrm{AP}}$ peaks, and the time limit is also similar in all cases. As in Figures 3(a) and 4(a), the peaks were normalized to the strength of the spectrum at $0.1 \mathrm{~Hz}$, and it should be remarked that the strength of the $P_{\text {Mo }}$ peak has increased in comparison with the peak $P_{\mathrm{AP}}$, indicating 


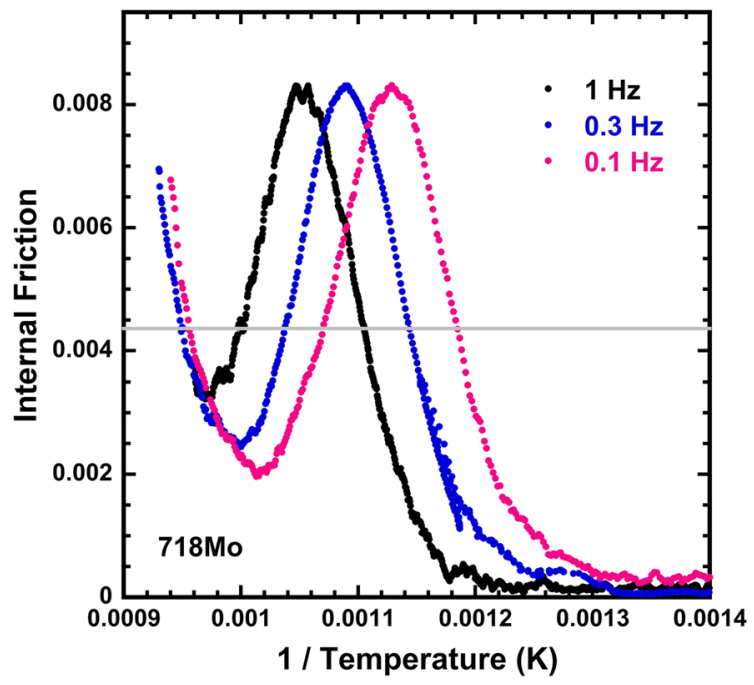

(a)

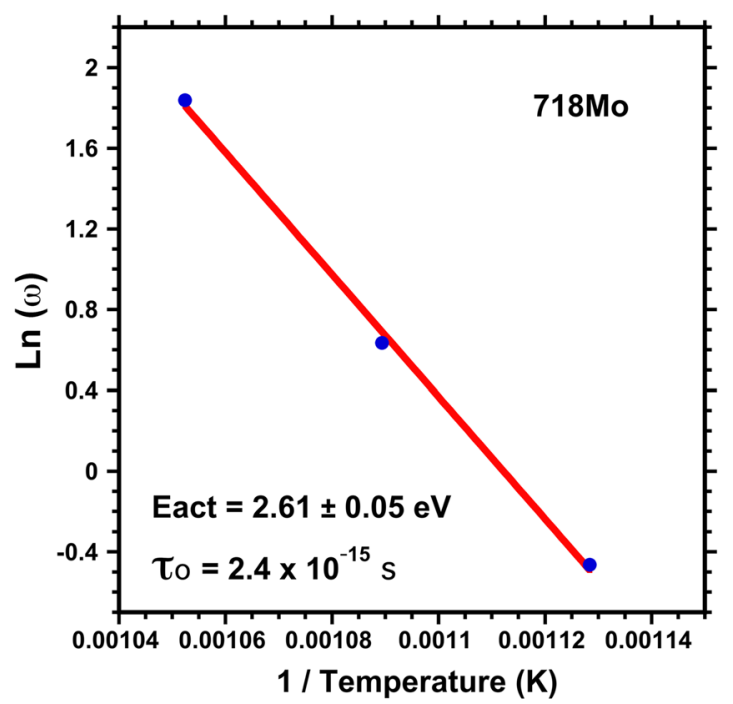

(b)

Fig. 6 - (a) IF spectra at three frequencies for the 718 Mo-rich alloy. The peaks were normalized to the strength of the spectrum at $0.1 \mathrm{~Hz}$. (b) Arrhenius diagram obtained from these spectra using Eq. [1] from the low-temperature side of the peaks.

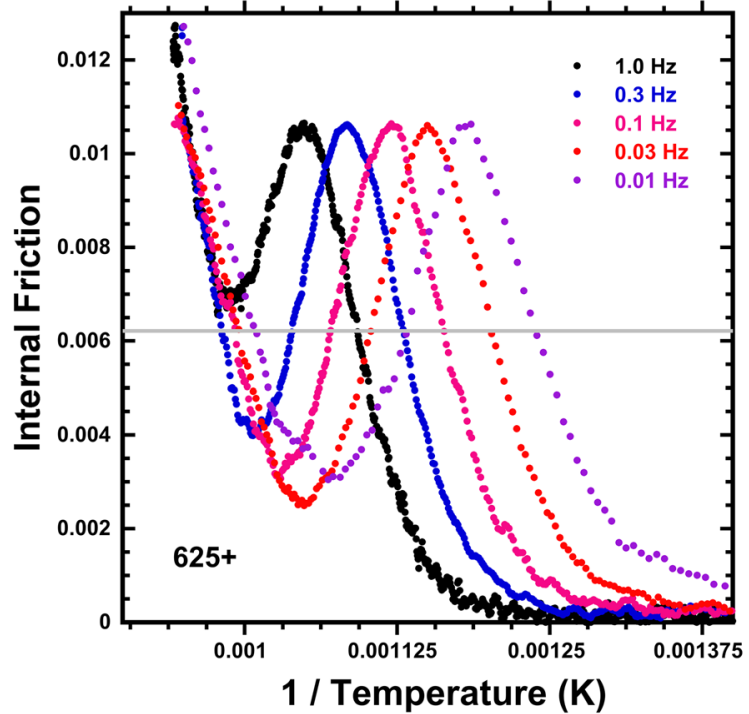

(a)

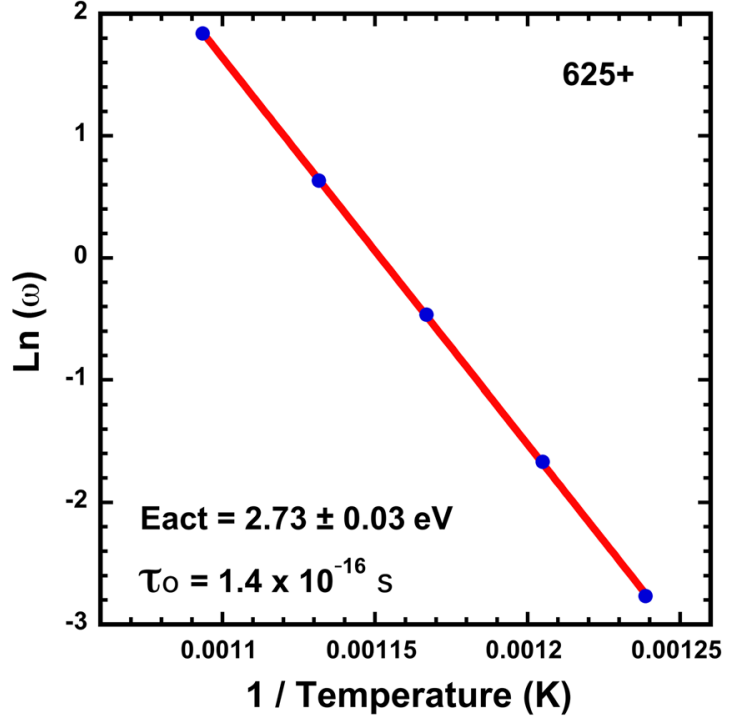

(b)

Fig. 7-(a) Series of IF spectra at different frequencies of the $625+$ alloy, bearing a high content ( 8 wt pct) of Mo. The peaks have been normalized to the strength of the spectrum at $0.1 \mathrm{~Hz}$. (b) Arrhenius diagram obtained from these spectra using Eq. [1] from the low-temperature side of the peaks.

that Mo could be responsible for the relaxation peak under study. To verify this point about the influence of Mo, as well as to test the influence of Fe, another alloy $625+$ still richer in Mo ( $8 \mathrm{wt}$ pct Mo) than the $718 \mathrm{Mo}$ and containing only a small amount of $\mathrm{Fe}$ ( 3 wt pct Fe), as indicated in Table I, was studied. This alloy received a thermal treatment similar to the standard aeronautical one. A strong decrease of the peak strength, in comparison with the 718AP (18.3 wt pet Fe) alloy, must be expected in the case that $\mathrm{Fe}$ would be responsible for the relaxation peak. In Figure 7(a), the spectra measured in
$625+$ alloy at five frequencies are plotted, normalized to the one at $0.1 \mathrm{~Hz}$, and the corresponding Arrhenius diagram is plotted in Figure 7(b). The activation energy of the peak $P_{625}$ is close to previous measurements, within the error bars, but its strength is clearly superior to the peak $P_{\mathrm{AP}}$ or even to $P_{\mathrm{Mo}}$. Then, from these last measurements, the Fe can be excluded as responsible for the relaxation peak, and Mo becomes the only atomic species that would explain the entire set of experimental results. However, before establishing a final conclusion, the role of the Mo should be carefully discussed. 


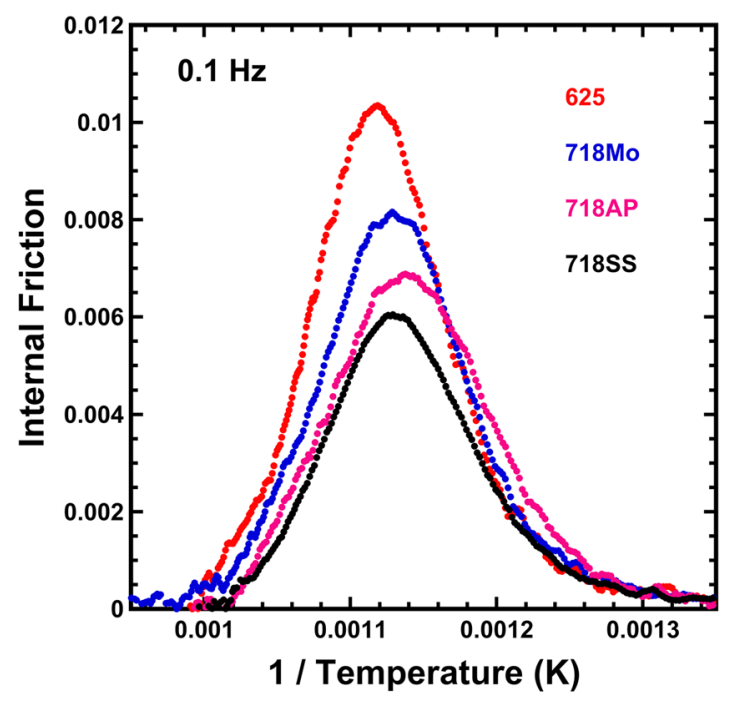

(a)

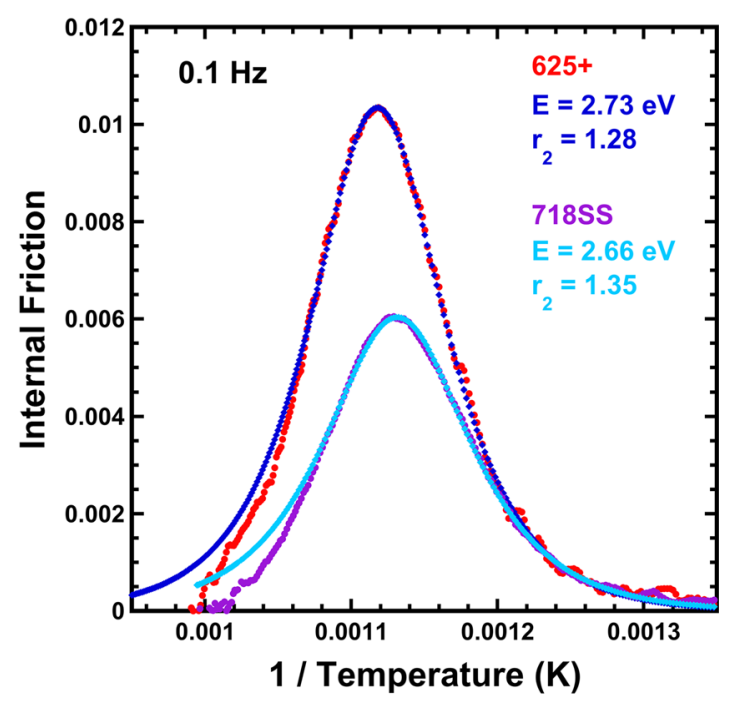

(b)

Fig. 8- (a) IF spectra measured at $0.1 \mathrm{~Hz}$, and after subtraction of the HTB, for the different alloys studied in the present work, to compare the dependence of the relaxation strength on the Mo concentration. (b) IF spectra for 718SS (violet dots) and 625+ (red dots) alloys, in comparison with the theoretical spectra fitted in both cases from Eq. [2], cyan and blue rhombuses, respectively, with the indicated parameters (Color figure online).

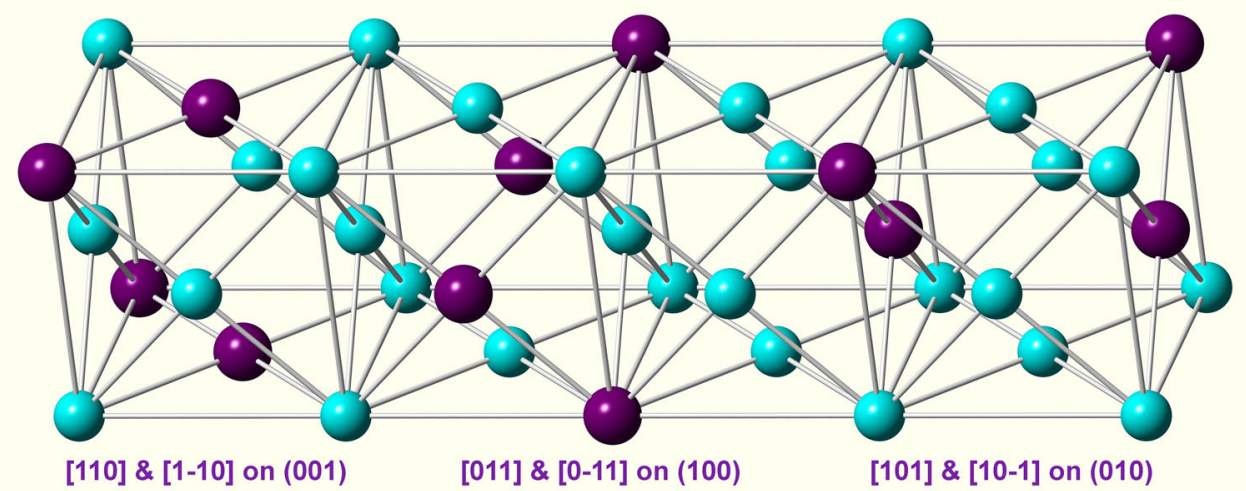

(a)

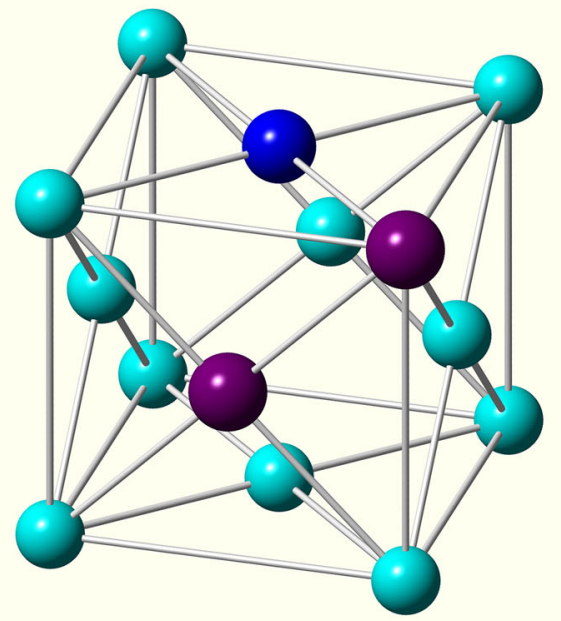

(b)

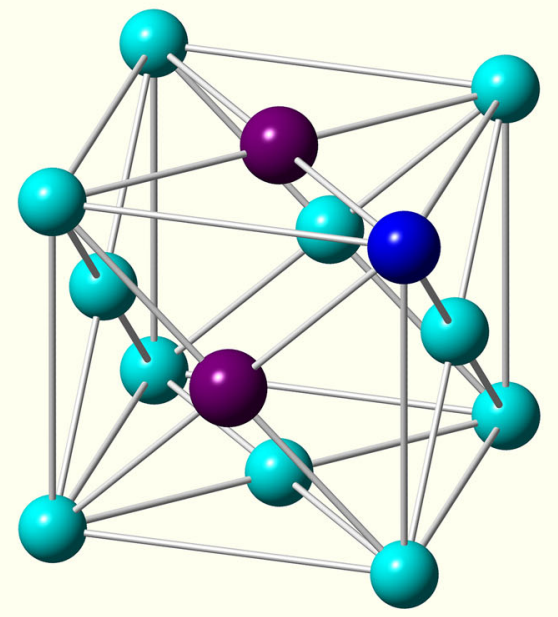

(c)

Fig. 9- (a) Schema of the six different Mo-Mo dipoles at NN (purple atoms), with $\langle 110\rangle$ orientations on $\{001\}$ planes and orthorhombic symmetry. (b) Presence of a vacancy (dark blue sphere) close to the [011](100) Mo-Mo dipoles due to their binding energy $E_{B}(\mathrm{Mo}-\mathrm{V}-\mathrm{Mo}$ ). (c) Stress-induced reorientation of the Mo-Mo dipoles to another equivalent [-101](010) orientation, under the applied oscillating stress, during IF measurements. See the video clip included in the supplementary information (Color figure online). 


\section{DISCUSSION}

During the inverse PLC effect, some substitutional solute atom undergoes a long distance diffusion process toward the dislocations due to the binding energy solute dislocation $E_{B}(\mathrm{SD})$. Then, in the temperature range in which the inverse PLC takes place ( $700 \mathrm{~K}$ to $950 \mathrm{~K}$ ), the long distance diffusion of the atomic species responsible for this effect must be triggered by short distance atomic jumps to activate the process. Reciprocally, if the motion of an atomic species is activated through short distance diffusion jumps in this temperature range, it will be a good candidate to be responsible for the PLC effect. With this approach, the presented experimental results give an enlightening view of the atomic species susceptible of being responsible for the observed relaxation peak. Indeed, the strength of the relaxation peak clearly increases with the solid solution concentration of Mo, as shown in Figure 8(a) in which the peak, measured at $0.1 \mathrm{~Hz}$ and after subtraction of the HTB, is plotted for the different studied alloys. The peak for the 718 SS alloy exhibits a strength of $\tan \left(\phi_{\max }\right)=6 \times 10^{-3}$, and the aeronautically treated 718AP alloy produces a slight increase of $\tan \left(\phi_{\max }\right)$, as expected due to the enrichment of the solid solution in Mo because of the precipitation. The addition of a higher amount of Mo in the $718 \mathrm{Mo}$ alloy clearly increases the relaxation strength to $\tan \left(\phi_{\max }\right)=8 \times 10^{-3}$. Finally, in the $625+$ alloy with 8 wt pct Mo, the strength of the IF peak reaches the maximum value of $\tan \left(\phi_{\max }\right)=10.5 \times 10^{-3}$. Another point can be made regarding Figure 8(a): the slight shift toward high temperature of the IF peaks in the precipitated samples when the amount of Mo increases. These results are in agreement with previous studies of PLC-DSA effects in the 718 Mo-rich alloy ${ }^{[54]}$ and in 625 alloy, ${ }^{[7]}$ in which the transition from PLC to DSA is found at slightly higher temperatures than in the case of 718 alloy presented in Figure 1. This behavior evidences again the correlation of the temperature and strain-rate domains between PLC and IF experiments. In Figure 8(b), the peaks for the extreme Mo concentrations are plotted together with the fit to the theoretical Eq. [2]. The fit is remarkably good, except in the last part of the high-temperature side for which the experimental spectra become slightly truncated because of the subtraction of the HTB.

The activation energies used for the fitting were the ones measured in Figures 3 and 7, and the best fit is obtained for a broadening factor of about $r_{2}=1.3$ ( $\beta=1.1)$, which means that the peak corresponds in all cases to a slightly broadened Debye peak that can only be attributed to a point defect mechanism. Then, it can be concluded that the observed relaxation peak is linked to Mo atoms, and we attribute this peak to a Zener relaxation $^{[57,58]}$ due to the stress-induced reorientation of Mo-Mo pairs of solute atoms. This mechanism is schematically presented in Figure 9 and can be described as follows. In a crystalline lattice with a concentration $\mathrm{C}$ of solute atoms, there is a probability of finding solute atom pairs at NN positions, which is proportional to $\mathrm{C}^{2}$. Each solute pair produces some local elastic strain of the lattice and constitutes an elastic dipole characterized by a strain ellipsoid according to the particular lattice symmetry. ${ }^{[24,58]}$ In the case of the fcc lattice of $\mathrm{Ni}$, the Mo-Mo dipoles will have six possible $\langle 110\rangle$ orientations at $\mathrm{NN}$ with orthorhombic symmetry, as depicted in Figure 9(a).

Under an applied stress, these dipoles are able to rotate by exchange of one Mo atom with a vacancy, as shown in Figures 9(b) and (c). During the IF measurement, the oscillating stress of angular frequency $\omega$ can stimulate the resonance of the reversible rotation of the dipoles when the condition $\omega \tau=1$ is fulfilled, giving place to the maximum relaxation strength of the peak with a relaxation time following the Arrhenius law. A video clip illustrating this process is included in the supplementary information. Then, the mean value of the measured activation energy $E_{\mathrm{a}}=2.68 \pm 0.05 \mathrm{eV}$ will be the one for the exchange of a Mo atom from the Mo-Mo dipole with a vacancy; this means the short distance diffusion energy for the Mo in the fcc lattice of Ni. This is the first time that the Zener relaxation of Mo is reported in Ni-base superalloys, but a similar Zener relaxation due to trigonal Mo-Mo pairs in the bcc lattice of the $\beta$ phase in Ti-Al-Mo alloys was recently reported ${ }^{[59]}$ Nevertheless, it should be remarked that the activation energy of the Zener relaxation should be slightly smaller than the one for long distance diffusion $^{[24,47]}$ due to the expected higher binding energy $E_{\mathrm{B}}(\mathrm{Mo}-\mathrm{V}-\mathrm{Mo})$ between the vacancy and the atom pair, in comparison with the binding energy $E_{\mathrm{B}}(\mathrm{Mo}-\mathrm{V})$ of the vacancy with a single atom. In any case, the short distance diffusion process involved in the anelastic relaxation will be the precursor to the long distance diffusion taking place during the PLC effect. One important point to consider is that the PLC effect requires a certain binding energy solute dislocation $E_{\mathrm{B}}(\mathrm{SD})$ to stimulate the diffusion of the solute atoms toward the volume surrounding the core of the dislocation. This is promoted for solute atoms producing a high local elastic strain of the lattice, which is further relaxed when such atoms migrate toward the environment of the dislocation core. Then, atoms such as $\mathrm{Cr}$ or $\mathrm{Fe}$ with practically the same atomic radius as $\mathrm{Ni}^{[60]}$ and producing a low distortion of the Ni lattice, ${ }^{[55]}$ must have a low binding energy $E_{\mathrm{B}}(\mathrm{SD})$. On the contrary, atoms with much larger atomic radius than $\mathrm{Ni}$, producing a high lattice distortion such as $\mathrm{Nb}$ and $\mathrm{Mo},{ }^{[55,60]}$ are the best candidates. The present results tend to rule out the responsibility of $\mathrm{Nb}$ for the anelastic relaxation phenomenon evidenced through this IF study, in agreement with the presence of the PLC effect in Nb-free alloy, ${ }^{[54]}$ and Mo emerges as the most suitable solute species to account for the occurrence of both phenomena [the short distance diffusion process generating the relaxation peak $P_{718}(\mathrm{Mo})$ and the long distance diffusion stimulated by the high binding energy $\left.E_{\mathrm{B}}(\mathrm{Mo}-\mathrm{D})\right]$ being responsible for DSA and leading to the occurrence of the high-temperature PLC effect in alloy 718.

\section{CONCLUSIONS}

Ni-base superalloys are prone to undergo DSA, which can induce mechanical instabilities, such as the PLC effect, over a wide range of strain rate and temperature. 
Two temperature regimes of PLC serration occurrence are often observed. The low-temperature regime is clearly associated to interstitial atoms with a prominent role of carbon atoms. With respect to the high-temperature regime of serrations, the identification of the atomic species of the solute responsible for this effect is still controversial. The present work focused on discriminating between the different solute atoms that could be responsible for the PLC effect in 718 alloy. Then, in light of the presented results and analysis, the following conclusions can be drawn.

1. Mechanical spectroscopy is a good alternative technique to identify the atomic species involved in strain aging because the short distance atomic jumps, taking place during the relaxation processes, will be precursors to the long distance diffusion mechanism required for the PLC effect.

2. In all the 718-type and $625+$ studied superalloys, a relaxation peak was found in the same temperature range, from $700 \mathrm{~K}$ to $950 \mathrm{~K}(885 \mathrm{~K}$ for $0.1 \mathrm{~Hz})$, in which the high-temperature PLC effect takes place, both processes being directly related to solute atom migration. A rationalization of the correlation between the strain-rate and temperature ranges in both experiments, PLC and IF, was presented.

3. The activation parameters of the relaxation peak observed in the different 718-type alloys as well as in $625+$ alloy were measured. The activation energy $E_{\mathrm{a}}\left(P_{718}\right)=2.68 \pm 0.05 \mathrm{eV}$, the pre-exponential time $\tau_{0}=2 \times 10^{-15} \pm 1$ s, and the Gaussian broadening $\beta=1.1$ clearly indicate that the peak is due to an atomic point defect relaxation.

4. The performed experiments on 718-type and 625+ alloys with different amounts of solid solution elements and thermal treatments, together with the clear dependence of the relaxation strength on the Mo concentration, allow us to conclude that the relaxation peak $P_{718}$ is associated with Mo solute atoms.

5. The relaxation peak can be attributed to the stress-induced reorientation of Mo-Mo dipoles by exchange of one Mo atom with a vacancy, according to the model of Zener relaxation.

6. Then, Mo solute atom diffusion can be considered to play a significant role in the PLC effect in 718 superalloy, with an activation energy close to the one measured for the relaxation peak.

We believe that our results and analysis constitute a step forward to closing the controversy concerning the nature of the atomic species responsible for the PLC in 718 alloy and pave the way for the design of a new generation of superalloys with improved mechanical properties.

\section{ACKNOWLEDGMENTS}

This work was supported by the Spanish Ministry of Economy and Competitiveness, MINECO, Project CONSOLIDER-INGENIO 2010 CSD2009-00013, as well as by the Consolidated Research Group IT-10-310, from the Education Department of the Basque Government, and GIU-17/071, from the University of the Basque Country UPV/EHU.

\section{ELECTRONIC SUPPLEMENTARY MATERIAL}

The online version of this article (https://doi.org/10. 1007/s11661-018-4579-2) contains supplementary material, which is available to authorized users.

\section{REFERENCES}

1. A.H. Cottrell: Rep. Conf. Strength Solids, Bristol, 1947, pp. 30-36.

2. A.H. Cottrell and M.A. Jaswon: Proc. R. Soc. A, 1949, vol. 199, pp. 104-14.

3. R.W. Hayes and W.C. Hayes: Acta Metall., 1982, vol. 30, pp. 1295-1301.

4. R.W. Hayes: Acta Metall., 1983, vol. 31, pp. 365-71.

5. M.C. Chaturvedi and I.S. Kim: Trans. Jpn. Ins. Met., 1987, vol. 28 , pp. 205-12.

6. V. Shankar, M. Valsan, K. Bhanu Sankara Rao, and S.L. Mannan: Metall. Mater. Trans. A, 2004, vol. 35A, pp. 3129-39.

7. A. Chatterjee, G. Sharma, R. Tewari, and J. Chakravartty: Metall. Mater. Trans. A, 2015, vol. 46A, pp. 1097-1107.

8. K. Gopinath, A.K. Gogia, S.V. Kamat, and U. Ramamurty: Acta Mater., 2009, vol. 57, pp. 1243-53.

9. M. Mazière, J. Besson, S. Forest, B. Tanguy, H. Chalons, and F. Vogel: Eur. J. Comput. Mech., 2008, vol. 17, pp. 761-72.

10. R. Sharghi-Moshtaghin and S. Asgari: Mater. Sci. Eng. A, 2008, vol. 486 , pp. $376-80$.

11. H. Dybiec: Arch. Metal. Pol., 1991, vol. 36, pp. 341-52.

12. W. Chen and M.C. Chaturvedi: Mater. Sci. Eng. A, 1997, vol. 229, pp. $163-68$.

13. C.L. Hale, W.S. Rollings, and M.L. Weaver: Mater. Sci. Eng. A, 2001, vol. 300, pp. 153-64.

14. M.L. Weaver and C.L. Hale: Miner. Met. Mater. Soc., 2001, pp. 421-32.

15. L. Fournier, D. Delafosse, and T. Magnin: Mater. Sci. Eng. A, 2001, vol. 316, pp. 166-73.

16. V. Garat, J.-M. Cloué, D. Poquillon, and E. Andrieu: J. Nucl. Mater., 2008, vol. 375, pp. 95-101.

17. B. Ter-Ovanessian, J. Deleume, J.-M. Cloué, and E. Andrieu: Mater. Sci. Forum, 2008, vols. 595-598, pp. 951-58.

18. S.A. Nalawade, M. Sundararaman, R. Kishore, and J.G. Shah: Scripta Mater., 2008, vol. 59, pp. 991-94.

19. S. Nalawade, S. Mahadevan, J.B. Singh, K. Ramaswamy, and A. Verma: Miner. Met. Mater. Soc., 2010, pp. 808-23.

20. B. Max, B. Viguier, E. Andrieu, and J.M. Cloue: Metall. Mater. Trans. A, 2014, vol. 45A, pp. 5431-41.

21. Y. Nakada and S. Keh: Acta Metall., 1970, vol. 18, pp. 437-43.

22. S. Venkadesan, C. Phaniraj, P.V. Sivaprasad, and P. Rodriguez: Acta Metall., 1992, vol. 40, pp. 569-80.

23. E. Pink: Scripta Metall., 1983, vol. 17, pp. 847-52.

24. A. Nowick and B. Berry: Anelastic Relaxation in Crystalline Solids, Academic Press, New York, 1972.

25. Mechanical Spectroscopy $Q-1$, ed., R. Schaller, and G. Fantozzi, and G. Gremaud, eds., Mechanical Spectroscopy $Q^{-1}$, Trans Tech Publications, Uetikon-Zurich, 2001.

26. J. San Juan: Mater. Sci. Forum, 2001, vols. 366-368, pp. 32-73.

27. I. Gutierrez-Urrutia, M.L. Nó, E. Carreño-Morelli, B. Guisolan, R. Schaller, and J. San Juan: Mater. Sci. Eng. A, 2004, vol. 370, pp. 435-39.

28. P. Simas, J. San Juan, and M. Nó: Mater. Sci. Eng. A, 2009, vol. 521, pp. 73-76.

29. J. San Juan, P. Simas, T. Schmoelzer, H. Clemens, S. Mayer, and M. Nó: Acta Mater., 2014, vol. 65, pp. 338-50. 
30. M. Castillo-Rodríguez, M. Nó, J. Jiménez, O. Ruano, and J. San Juan: Acta Mater., 2016, vol. 103, pp. 46-56.

31. J.W. Brooks and P.J. Bridge: Superalloys 1988, TMS, Warrendale, PA, 1988, pp. 33-42.

32. A. Oradei-Basile and J.F. Radavich: Superalloys 718, 625 and Various Derivatives, TMS, Warrendale, PA, 1991, pp. 325-35.

33. R. Swalin and A. Martin: J. Met., 1956, vol. 8, pp. 567-72.

34. N. Matan, H. Winand, P. Carter, M. Karunaratne, P. Bogdanoff, and R. Reed: Acta Mater., 1998, vol. 46, pp. 4587-4600.

35. A. Engström and J. Agren: Z. Met., 1996, vol. 87, pp. 92-97.

36. M. Karunaratne, P. Carter, and R. Reed: Acta Mater., 2001, vol. 49 , pp. 861-75.

37. R.V. Patil: J. Nucl. Mater., 1996, vol. 230, pp. 57-60.

38. M.S.A. Karunaratne and R.C. Reed: Def. Diffus. Forum, 2005, vols. 237-240, pp. 420-25.

39. J.R. MacEwan, J.U. MacEwan, and L. Yaffe: Can. J. Chem., 1959, vol. 37 , pp. 1629-36.

40. S. Rothman, L. Nowicki, and G. Murch: J. Phys. F, 1980, vol. 10, pp. 383-90.

41. C.J. Smithels: Metal Reference Book, Metal Powder Industry Federation, Princeton, NJ, 1994.

42. D. Pruthi, M. Anand, and R. Agarwala: J. Nucl. Mater., 1977, vol. 64 , pp. 206-10.

43. C. Campbell, W. Boettinger, and U. Kattner: Acta Mater., 2002, vol. 50, pp. 775-92.

44. Y. Minamino, H. Yoshida, S.B. Jung, K. Hirao, and T. Yamane: Def. Diff. Forum, 1997, vols. 143-147, pp. 257-62.

45. V. Divya, S. Balam, U. Ramamurty, and A. Paul: Scripta Mater., 2010, vol. 62, pp. 621-24.
46. D. Batist: Internal Friction of Structural Defect in Crystalline Solids, North-Holland Publishing Co., Amsterdam, 1972.

47. M. Weller: Mater. Sci. Forum, 2001, vols. 366-368, pp. $95-140$.

48. M.S. Blanter, I.S. Golovin, H. Neuhäuser, and H.-R. Sinning: Internal Friction in Metallic Materials: A Handbook, Springer, Berlin, 2007.

49. M.K. Miller, S.S. Babu, and M.G. Burke: Mater. Sci. Eng. A, 2002, vol. 327, pp. 84-88.

50. P. Gadaud and K. Chakib: Mater. Sci. Forum, 1993, vols. 119-121, pp. 397-400.

51. A. Mourisco, N. Baluc, J. Boneville, and R. Schaller: Mater. Sci. Eng. A, 1997, vols. 239-240, pp. 281-86.

52. H. Numakura, N. Nurita, M. Koiwa, and P. Gadaud: Philos. Mag. A, 1999, vol. 79, pp. 943-53.

53. H. Numakura and K. Nishi: Mater. Sci. Eng. A, 2006, vol. 442, pp. 59-62.

54. B. Max: Ph.D. Thesis, University of Toulouse, Toulouse, 2014.

55. A. Jena and M. Chaturvedi: J. Mater. Sci., 1984, vol. 19, pp. 3121-39.

56. B. Cao, R. Schaller, W. Benoit, and F. Cosandey: J. Alloys Compd., 1994, vol. 211, pp. 118-23.

57. C. Zener: Phys. Rev., 1947, vol. 71, pp. 34-38.

58. C. Zener: Elasticity and Anelasticity of Metals, University of Chicago Press, Chicago, 1948.

59. L. Usategui, M. Nó, S. Mayer, H. Clemens, and J. San Juan: Mater. Sci. Eng. A, 2017, vol. 700, pp. 495-502.

60. M.C. Ball and A.H. Norbury: Physical Data for Inorganic Chemists, Longman, London, 1974. 